www.jmscr.igmpublication.org

Impact Factor 5.84

Index Copernicus Value: 71.58

ISSN (e)-2347-176x ISSN (p) 2455-0450

crossref DOI: _https://dx.doi.org/10.18535/jmscr/v5i12.87

Journal Of Medical Science And Clinical Research

\title{
Maternal Mortality in a Tertiary Care Hospital of Central India: A 5 years Review
}

\author{
Authors \\ Dr Rushali Rajan Lilare ${ }^{1}$, Dr Uday W. Narlawar ${ }^{2}$, Rajat Lillore ${ }^{3}$ \\ ${ }^{1}$ Pl No 16 Gayatri Nagar Baba Farid Nagar Koradi Road Nagpur 440030 \\ ${ }^{2}$ Department of Community Medicine, Govt Medical College, Hanuman Nagar, Nagpur \\ ${ }^{3}$ R-10 Prathamesh Apartment Laxmi Nagar Nagpur
}

\begin{abstract}
The key to the progress of a country lies in reducing it's maternal morbidity and mortality. The maternal mortality rate has gone down since 1980 however it has still not achieved the target level hence to give a better assessment to the problem of maternal mortality, a retrospective study on maternal mortality ratio and it's causes has been carried out.

Objective of the study was to find out the maternal mortality ratio and its causes of five years (2012-2016) in a tertiary care hospital situated in Central India.

Methods: A retrospective study done at a tertiary level care centre from January 2012 to December 2016. Data was collected of maternal death from medical record section. Data studied and analysed.

Results: The mean maternal mortality ratio was recorded 555.84 per 100000 live births. Highest in the year 2016 i.e 632 per 100000 live births and the lowest maternal mortality ratio was in the year 2013 i.e 404 per 100000 live births. Maternal mortality was more than 80\% among the age group of 20-30 years as compare to the $<20$ years and $>30$ years. About $65.8 \%$ of maternal death were due to the direct causes and $34.2 \%$ were due to the indirect causes. The leading direct cause was sepsis $(34.2 \%)$, while indirect $(18.35 \%)$ leading cause was infectious disease (15.7\%).

Conclusion: Being the tertiary care hospital where patients were referred from the periphery the maternal mortality ratio which was record based was found to be on higher side. Direct causes contributes more as compare to indirect causes. So emphasis should be made to reduce the maternal mortality by early registration, regular $A N C \&$ \&NC visit, early detection of complication \& it's prevention, early identification of high risk pregnancies and timely referral to higher centre.

Keywords: Maternal mortality, sepsis, infectious disease.
\end{abstract}

\section{Introduction}

World Health Organization (WHO) defines maternal death as, "Death of a woman while pregnant or within 42 days of termination of pregnancy, irrespective of the duration and site of pregnancy, from any cause related to or aggravated by pregnancy or its management."
According to UNICEF, worldwide sub-Saharan Africa and South Asia, contributes for 88 per cent of maternal deaths worldwide where $66 \%$ of all maternal deaths is contributed by sub-Saharan Africa \& $22 \%$ by South Asia per year. At the country level India contributes one-fifth to the global maternal mortality. ${ }^{1}$ 
According to WHO the maternal mortality ratio of developing countries in 2015 is 239 per 100000 live births, twenty times higher than developed countries. ${ }^{2}$ Millennium Development Goal 5 calls for a $75 \%$ reduction in the maternal mortality ratio (MMR) between 1990 and 2015 but the maternal mortality ratio fell by nearly $44 \%$ over the past 25 years. As part of the Sustainable Development Goals, the target is to reduce the global maternal mortality ratio to less than 70 per 100000 live births between 2016 and 2030.

Maternal Mortality Ratio (MMR) In India has shown a decline from 178 per 100,000 live births in the period $2010-12$ to 167 per 100,000 live births in the period 2011- $13 .{ }^{3,4}$ Currently maternal mortality ratio (MMR) in India is $167 / 100,000$ live birth and of Maharashtra is /100,000 live birth. ${ }^{4}$ About $80 \%$ of maternal mortality occurs due to direct causes and obstetric haemorrhage being the commonest. ${ }^{5}$ Government of India is continuously trying to reduce maternal mortality below the target level via various programmes like Child survival and safe motherhood, RCH , NHM etc

This study was done to assess the maternal mortality ratio \& its causes in a tertiary care hospital situated in Central India.

\section{Materials and Methods}

The present study was conducted at the tertiary care hospital of Central India. The present study was a retrospective study, conducted in the department of Community Medicine of the hospital. Data regarding maternal mortality was collected from Maternal Mortality Register after obtaining permission from the Medical Record section of the hospital. The details of maternal deaths over 5 years, from January 2012 to December 2016 were collected and analysed. There were total 305 maternal deaths over the above mention period of 5 years. Descriptive data was tabulated as absolute figures and percentages.
The details of number of live births from January 2012 to December 2016 were collected from Medical Record section.

Maternal mortality ratio for the study period was calculated by using the formula-

$$
\text { MMR }=\frac{\text { Totalno of maternal deaths }}{\text { Total no of live births }} \times 100000
$$

The ethical committee of the institute had given approval for the study.

\section{Results}

- In the present study, "Maternal Mortality in a Tertiary Care Hospital of Central India" maternal mortality ratio from 2012-2016 was highest in the year 2016 i.e 632 and lowest in the year 2013 i.e 404 . The maternal mortality ratio of the year 2012, 2015 and 2014 was 596, 585 and 568 respectively.(Figure-1)

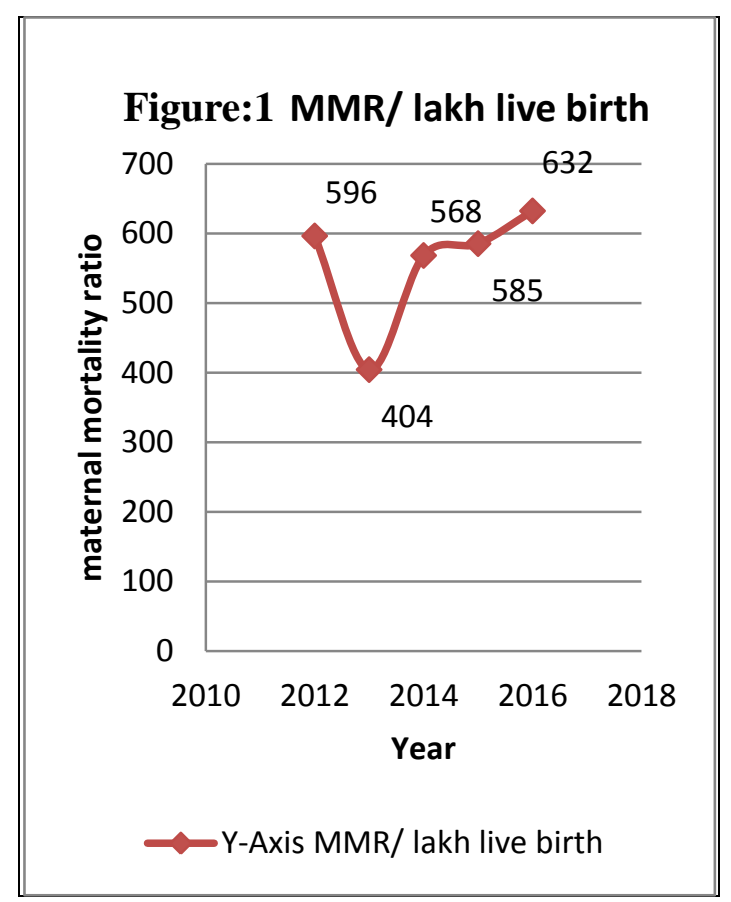

- Between 20-30 years of age group from 2012-2016 the maternal mortality was $87.4 \%, 86.6 \%, 81.3 \%, 80.9 \%$ and $83.1 \%$ respectively. (Figure-2) 


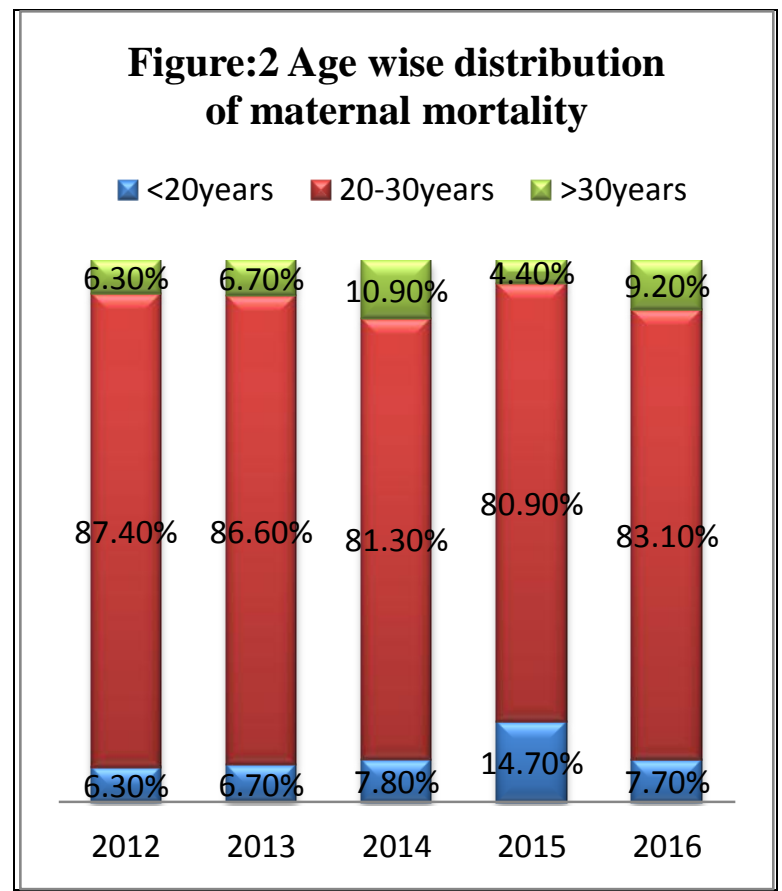

- Maternal mortality from the year 2012-2016, $58.7 \%, 75.6 \%, 70.3 \%, 63.2 \%$ and $64.6 \%$ were due to direct causes whereas $41.3 \%$, $24.4 \%, 29.7 \%, 36.8 \%$ and $35.4 \%$ were due to indirect causes respectively. (Figure-3)

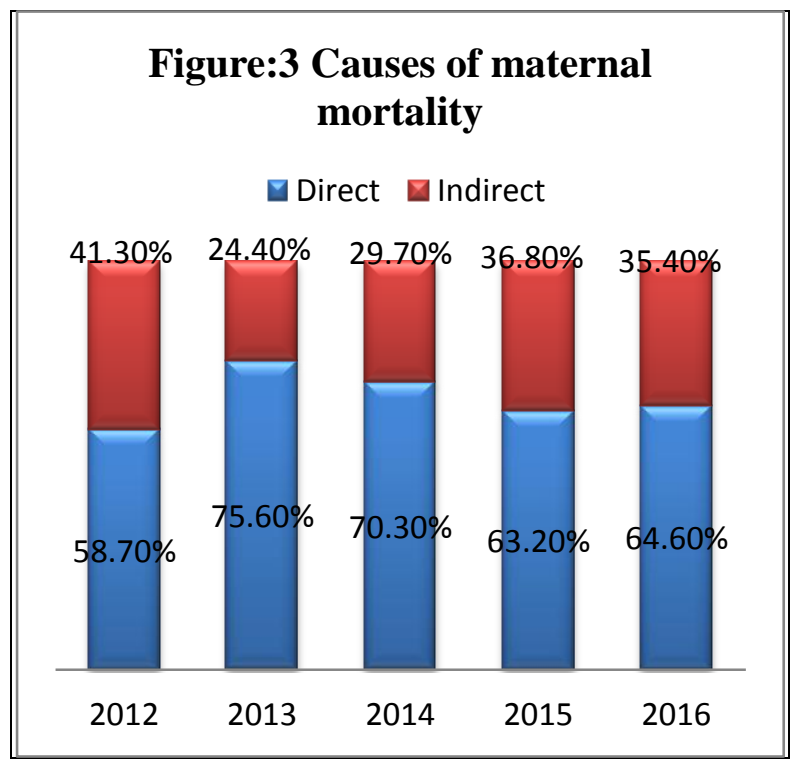

- The present study reveals that $65.8 \%$ were the direct causes of maternal mortality and $34.2 \%$ were the indirect causes of maternal mortality. Among the direct causes $30.8 \%$ mortality were due to sepsis / shock/MODS, \& $15.4 \%$ maternal mortality were due PIH/ eclampsia / HELLP syndrome whereas $7.2 \%$ mortality were due to haemmorage. (Figure4)

- Among the indirect causes infectious diseases contributed to $15.7 \%$ of maternal death. the Infectious diseases comprises of 21(7.9\%) hepatitis, 11(3.6\%) malaria, $5(1.6 \%)$ Dengue, 4(1.3\%) Bronchopneumonia, $3(0.98 \%)$ Swine FLU and $1(0.33 \%)$ each of Thyphoid, chicken pox, HbsAg and TB contributed to maternal death from 2012-2016. (Figure-5)

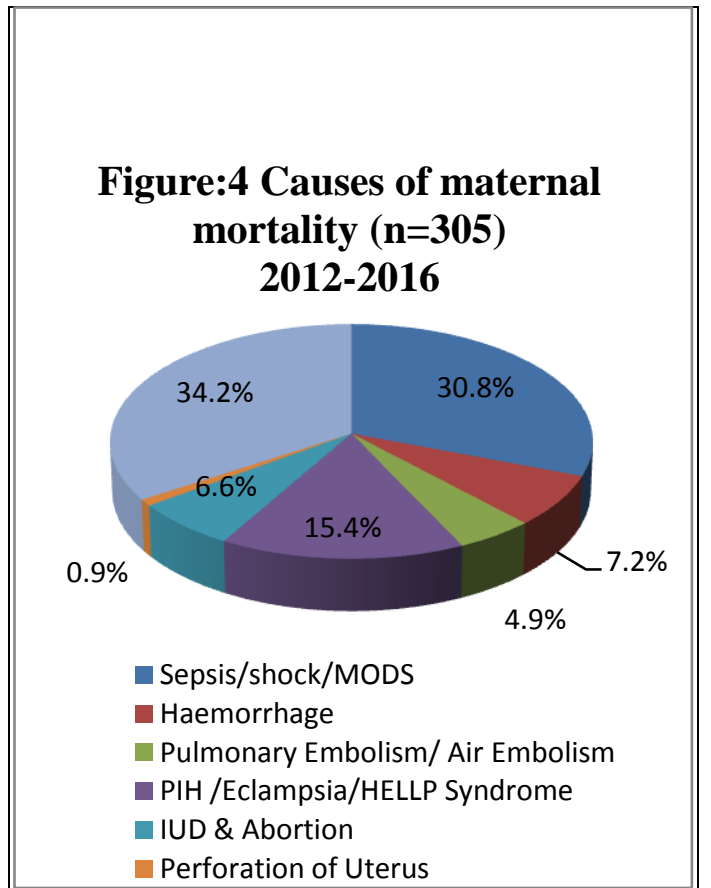

Figure: 5 Indirect causes of maternal mortality $(n=305)$

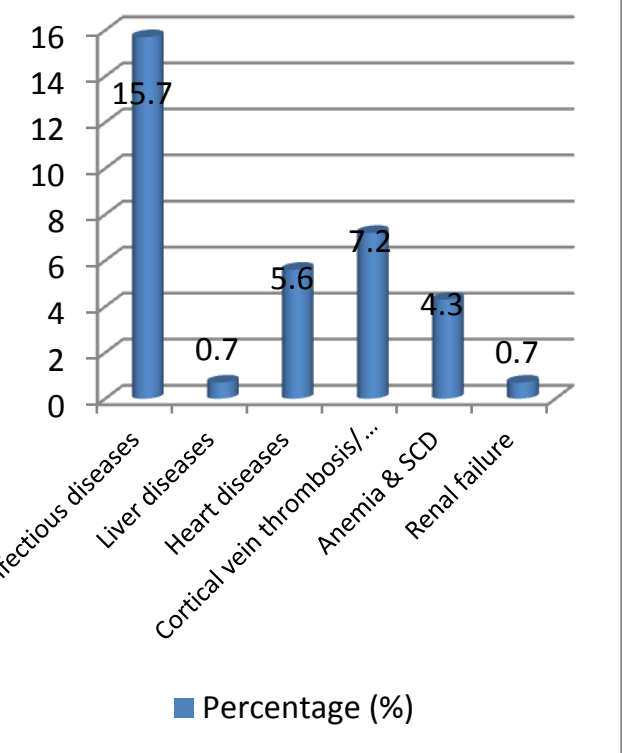




\section{Discussion}

MMR represent the risk associated with each pregnancy. It is also a MDG indicator. Death of a mother is loss not only to a family but also to the community and to the nation. In the present study there were 305 maternal death with 5471 live births from 2012-2016. The mean MMR was 555.84. More than 80 percent of maternal death occurred among the age group of 20-30 years with more than 50 percent death due to direct causes. Among the direct causes, the leading was sepsis.Infectious diseases being the leading cause among the indirect causes.

In our study MMR (2012- 2016) was calculated as 555.84. Various studies done in India in the last 15 years have shown wide variation in MMR ranging from $47 / 100000$ to $625 / 100000$ births. ${ }^{6-11}$ This study has comparatively high MMR, which could be due to the fact, that being a tertiary care centre it receives referrals from peripheral hospitals.

With the introduction and implementation of various national health programmes e.g. CSSM, $\mathrm{RCH}$,NHM etc an awareness has increased among the people not only toward heath leading to more number of cases getting referred to tertiary care hospital leading to increase in MMR.

In the present study out of 305 maternal death $83.6 \%$ occurs between 20-30years.In the study by Bhaskar K Murthy et al $70 \%$ of maternal deaths were in the age group of 20 to 29 years. ${ }^{12}$ Surekha N. Khandale, Kshama Kedar et al in their study found that $78.19 \%$ of maternal deaths were in the age group of 18-30 years. ${ }^{13}$ However, Ratan Das et al in their study had found that out of total 256 deaths, $93(36.32 \%)$ were in the age group of $19-24$ years followed by $79(30.85 \%)$ deaths in <19 years. ${ }^{14}$

In our study $65.9 \%$ maternal deaths were due to direct causes and $34.1 \%$ were due to indirect causes. Similarly, in the study by Ratan Das, $61.51 \%$ of maternal deaths were due to direct causes. ${ }^{14}$ Whereas in the study by Vidyadhar B. Bangal, Purushottam A. Giri et al both direct and indirect causes contributed to $(50.00 \%)$ of maternal death. ${ }^{15}$ In the present study among the direct causes sepsis 94(30.8\%) followed by 47(15.4\%) PIH/Eclampsia/ HELLP syndrome, 22(7.2\%), haemorrhage,
20(6.6\%) IUD\& Abortion, 15(4.9\%) Pulmonary embolism /Air Embolism and 3(0.9\%) Perforation of uterus contributed to maternal mortality.

In contrast to our study Surekha N. Khandale, Kshama Kedar et al in their study found that Eclampsia and preeclampsia (28.19\%), anaemia (14.10\%), Haemorrhage (10.25\%) were main direct causes of obstetric death. ${ }^{13}$ Vidyadhar B. Bangal, Purushottam A. Giri et al found that common direct causes were $(21.05 \%)$ hemorrhage, (10.52\%) eclampsia and pulmonary embolism and $(7.89 \%)$ sepsis. ${ }^{15}$

We found that among the indirect causes, infectious diseases were the leading causes contributing to 4(15.7\%). Among the infectious diseases 21(7.9\%) hepatitis leads to majority of maternal deaths. Other indirect causes includes Cortical vein thrombosis/ Cerebro vascular accidents 22(7.2\%), heart diseases 17(5.6\%), Anemia \& SCD 13(4.3\%), Liver diseases and Renal failure $2(0.7 \%)$ each.

In contrast to our findings in one of the study ARDS, hepatitis, heart disease accounted for $7.69 \%$, $6.41 \%$ and $5.12 \%$ of maternal deaths respectively. ${ }^{13}$ In study by Ratan Das founded that $17(6.64 \%)$ heart diseases, $15(8.85 \%)$ Cerebro vascular accident, 8 $(3.12 \%)$ renal failure and $7(2.74 \%)$ anemia contributes indirect causes of maternal death. ${ }^{14}$

\section{Conclusion}

In our study the maternal mortality ratio has been recorded at the higher side with majority of death occurring between 20-30years of age group. Direct causes contributes more to the maternal deaths as compare to indirect causes. Among the direct causes sepsis being the leading cause of maternal mortality.

\section{Limitation}

Record based study conducted at govt medical college hospital result cannot be generalised.

Funding: No funding sources

Conflict of interest: None declared

Ethical approval: The study was approved by the Institutional Ethics Committee 


\section{References}

1. UNICEF data. Maternal mortality fell by almost half between 1990 and 2015.

2. Estimates by WHO, UNICEF, UNFPA, World Bank Group and the United Nations Population Division. Trends in Maternal Mortality: 1990 to 2015

3. Special Bulletin on Maternal Mortality in India 2010-12: Sample registration system, Office of Registrar General, India. 2013 Dec.

4. Special Bulletin on Maternal Mortality in India 2011-13: Sample registration system, Office of Registrar General, India.

5. K. Park. Park's textbook of preventive and social medicine: $23^{\text {rd }}$ edition, Bhanot publiccations; preventive medicine in obstetrics, paediatrics and geriatrics, page no 559.

6. Puri A, Yadav, Jain N. Maternal mortality in an urban care hospital of north Insia. J Obstet Gynaecol India. 2011;61:280-5.

7. Jain M, Maharaje S, Maternal mortality: A retrospective analysis of ten years in a tertiary care hospital. Indian J Prev Soc Med. 2003;34:103-11.

8. Jadhav AJ, Rote PG. Maternal mortalitychanging trends. J Obstet Gynaecol India. 2007;57:398-400.

9. Pal A, Ray P, Hazra S, Mondal TK. Review of changing trends in maternal mortality in a rural medical college in west Bangal. J Obstet Gynecol India. 2005;55:521-4.

10. Onakewhor JU, Gharoro EP. Changing trends in maternal mortality in a developing country. Niger J Clin Pract. 2008;11:111-20.

11. Shah RJ, AliI, Banday A, Faziili A, Khan I. Analysis of maternal mortality in a small teaching hospital attached to tertiary care hospital. Indian J Community Med. 2008;33:260-2.

12. Bhaskar K Murthy, Mangala B Murthy, and Priya M Prabhu.Maternal Mortality in a Tertiary Care Hospital: A 10year Review; Int J Prev Med. 2013 Jan; 4(1): 105-109
13. Surekha N. Khandale, Kshama Kedar. Analysis of maternal mortality: a retrospective study at tertiary care centre Int J Reprod Contracept Obstet Gynecol. 2017 Apr;6(4):1610-1613

14. Ratan Das, Soumya Biswas and Amitava Mukherjee.Maternal Mortality at a Teaching Hospital of Rural India: A Retrospective Study; IJBAR (2014) 05 (02)

15. Vidyadhar B. Bangal, Purushottam A. Giri , Ruchika Garg. Maternal Mortality at a Tertiary Care Teaching Hospital of Rural India: A Retrospective Study Int J Biol Med Res. 2011; 2(4): 1043 - 1046. 